\title{
A pharmaco-epidemiological study of antibacterial treatments and bacterial diseases in Norwegian aquaculture from 2011 to 2016
}

\author{
Atle Lillehaug ${ }^{1, *}$, Christine Børnes $^{2}$, Kari Grave ${ }^{1}$ \\ ${ }^{1}$ Norwegian Veterinary Institute, 0106 Oslo, Norway \\ ${ }^{2}$ Norwegian Food Safety Authority, 5006 Bergen, Norway
}

\begin{abstract}
The sales and prescription of antibacterials for use in Norwegian fish-farming according to diagnosis, fish species and production stage from 2011 to 2016 are analysed. The study is based on antibacterial sales data from wholesalers, pharmacies and feed mills and on prescription data obtained from a register of all prescriptions of antibacterials used in farmed fish. The results show that the fish-farming industry uses very small volumes of antibacterials. In 2016, a total of $212 \mathrm{~kg}$ were sold; the only antibacterial substances sold were florfenicol and oxolinic acid. The total amount corresponded to $0.16 \mathrm{mg} \mathrm{kg}^{-1}$ fish slaughtered, or to approximately $0.14 \%$ of the fish produced that year. The majority of prescriptions were for non-specific bacterial infections; as most common diseases are under control by vaccination. Most prescriptions for salmonid fish were during early production stages. However, due to higher biomasses of fish, the highest quantities of antibacterials were prescribed during the seawater production phase of Atlantic salmon Salmo salar. An increasing proportion of the prescriptions was for other species, including cleaner fish used for salmon lice control; in 2016 most prescriptions were for this fish category. Due to the negligible use of antibacterials in Norwegian aquaculture, in particular for on-growers, the risk of development of antimicrobial resistance and its transmission to humans through consumption of fish is considered negligible.
\end{abstract}

KEY WORDS: Pharmaco-epidemiology $\cdot$ Aquaculture $\cdot$ Antibacterials $\cdot$ Prescriptions $\cdot$ Antibacterial sales $\cdot$ Fish diseases $\cdot$ Bacterial disease $\cdot$ Food safety

\section{INTRODUCTION}

In the 1980s, the fast growth of fish farming in Norway, in particular of Atlantic salmon Salmo salar, was accompanied by recurrent problems with disease outbreaks caused by bacterial infections, leading to a high consumption of antibacterial agents (Grave et al. 1990). Vibriosis, caused by Vibrio anguillarum, was already a major problem in the 1970 s, especially in rainbow trout Oncorhynchus mykiss raised in seawater (Håstein 1975). Vaccines against vibriosis were introduced in 1977, and during the following $10 \mathrm{yr}$, this was the only disease against which fish were vaccinated in Norwegian aquaculture (Lillehaug 1989). In 1987,

*Corresponding author: atle.lillehaug@vetinst.no cold-water vibriosis caused by Aliivibrio salmonicida (earlier Vibrio salmonicida) in Atlantic salmon resulted in the highest consumption of antibacterials in the Norwegian aquaculture industry that has ever been recorded (Grave et al. 1990). Vaccines against this disease were introduced the same year (Lillehaug 1990), and in the following $2 \mathrm{yr}$, sales of antibacterials declined significantly (Grave et al. 1990).

Furunculosis, caused by Aeromonas salmonicida subsp. salmonicida, was introduced in Norwegian aquaculture in 1985 and spread to almost all marine fish farm locations during the next years (Egidius 1987). Vaccines became available from 1987, and systematic field testing of these started in 1989 (Lille-

(C) The authors 2018. Open Access under Creative Commons by Attribution Licence. Use, distribution and reproduction are unrestricted. Authors and original publication must be credited. 
haug et al. 1992). The vaccine products were bacterins of $A$. salmonicidia containing aluminium salts as adjuvants. Although the vaccines were shown to provide some protection, and the sales of these vaccines increased during 1989 to 1992, only a moderate reduction in the use of antibacterial agents for fish farming was observed from 1990 to 1992 (Grave et al. 1996). Oil-adjuvanted vaccines against furunculosis became available in autumn 1992 (Midtlyng 1997), and by the end of 1993, almost all salmon and rainbow trout fingerlings had received an oil-adjuvanted furunculosis vaccine, as well as vaccines against vibriosis and cold-water vibriosis, before being transferred to seawater cages for on-growth (Markestad \& Grave 1997). Since the 1990s, antibacterial sales into the Norwegian fish farming industry have decreased dramatically due to introduction of effective vaccines against the major bacterial diseases and the implementation of the full-scale vaccination programs (Grave et al. 1999, Lillehaug et al. 2003, Markestad \& Grave 1997).

During the last $20 \mathrm{yr}$, the fish farming industry in Norway has steadily increased, from approx. 280000 $\mathrm{t}$ of fish produced in 1995 to 1.4 million $\mathrm{t}$ in 2015. In the present study, the overall sales and prescription patterns of antibacterial agents are described in relation to the current status of bacterial diseases in fish farming in Norway, categorised by fish species and production stage. The assessment uses sales and prescription data for antibacterial veterinary medicinal products (VMPs) for the period 2011 to 2016.

\section{METHODS}

\section{Data material}

Fish farming. Data on production (t) of farmed fish were obtained from the Directorate of Fisheries (www.fiskeridir.no).

Antibacterial sales. Sales data from wholesalers, pharmacies and feed mills of antibacterials for use in farmed fish are collected and published annually by the Norwegian Institute of Public Health $\left(\mathrm{NIPH}_{\text {; }}\right.$ www.fhi.no). The wholesalers, pharmacies and feed mills are mandated to report the sales to NIPH, which established systems for collecting such data $>25 \mathrm{yr}$ ago.

Prescriptions. In Norway, VMPs for use in animals, including farmed fish, are available by prescription only and have to be dispensed to the end-user (prescriber or farmer) by a pharmacy, wholesaler or an authorised feed mill.
From January 2011, it became mandatory to report all prescriptions of VMPs for use in farmed fish, including for premixes administered through feed, to the veterinary prescription register (VetReg) at the Norwegian Food Safety Authority (NFSA; www. mattilsynet.no). Pharmacies, wholesalers and feed mills report data from all dispensed prescriptions to VetReg. VMPs administered to animals or handed out to the animal owners from veterinarians or fish health biologists are also reported to VetReg. According to the guidance for VetReg, the reporting has to take place within $7 \mathrm{~d}$ after dispensing or handing out the VMPs or medicated feed.

Because antibacterial agents are typically administered to the fish through feed, prescriptions for the years 2011 to 2016 were reported almost solely by feed mills. Only 20 prescriptions, out of the total of 784 prescribed during the study period, were dispensed by pharmacies/wholesalers, and of these, 13 were products for bath treatment of fry and 7 were for injection of brood fish.

The prescriptions are usually submitted electronically (email), using a standard prescription form containing all the information to be reported to VetReg. In rare cases, the prescription is issued by phone.

The web application for reporting prescription data to VetReg is designed to ensure that the data reported are standardized, i.e. it includes drop-down lists with standardised terms.

Data reported to VetReg include:

- Date of prescription

- Prescriber: unique ID number, name

- Farm location: unique ID number

- Fish species: Atlantic salmonSalmo salar, rainbow trout Oncorhynchus mykiss, cod Gadus morhua, halibut Hippoglossus hippoglossus, turbot Psetta maxima, wolf fish Anachichas lupus, ballan wrasse Labrus bergylta, and the category 'others'

- Production phase: fry, fingerlings, on-growers, brood fish

- Number of fish to be treated and average fish weight

- Diagnosis: specific bacterial agent/disease (coldwater vibriosis, vibriosis, Vibrio infection, Aeromonas infection, yersiniosis, winter ulcers), and the category 'Bacterial infection - unspecified bacterial agent'

- Antibacterial agent: unique ID number, ATCvet names (Anatomical Therapeutic Chemical Classification System for Veterinary Medicinal Products (World Health Organization 2017), name of product, formulation (e.g. as medicated feed)

- Amount of antibacterial agent prescribed: weight of active substance in $\mathrm{kg}$ 
The antibacterial agent is prescribed as the total volume of medicated feed, with a given concentration of the antibacterial agent. Before reporting prescription data to VetReg, the total amount of active substance prescribed is calculated manually by the feed mill staff. The feed mills' staff subsequently upload the required data manually through the VetReg web interface (Norwegian Food Safety Authority, www.mattilsynet.no).

\section{Indicators for consumption of antibacterials}

Since fish are poikilothermic, the feed intake varies with temperature, and therefore the total amount of medicated feed needed to complete a treatment course for a specific fish population is prescribed considering prevailing water temperatures. This measurement takes into account differences in dosing between the various antibacterials, as well as between the different administration routes. For the present study, national defined course doses (DCD) for antibacterials per $\mathrm{kg}$ fish were applied for the analysis of the sales data; for oral treatment, the DCD used for florfenicol was $100 \mathrm{mg} \mathrm{kg}^{-1}$, for oxolinic acid $150 \mathrm{mg}$ $\mathrm{kg}^{-1}$ and for oxytetracycline $800 \mathrm{mg}$ $\mathrm{kg}^{-1}$ (Felleskatalogen, www.felleskata logen.no; Grave et al. 1996). Numbers of DCDs sold provide an estimate of the biomass in $\mathrm{kg}$ of farmed fish that could be treated with 1 cure with the volume antibacterials prescribed that year (numerator), designated as biomass treated per annum. The total biomass of fish slaughtered annually (see Table 1) was applied as a surrogate for the population at risk (denominator) of being subjected to treatment with antibacterials.

In the present paper, the amounts of antibacterials used are expressed as $\mathrm{mg} \mathrm{kg}^{-1}$ fish produced, based on the total volume of antibacterials sold (Norwegian Institute of Public Health, www.fhi.no) and the total biomass of fish slaughtered the same year.

\section{Diagnoses for antibacterial treatment}

Numbers of treatments with antibacterials were systemised according to year, diagnosis, fish species, production phase and fish size.

\section{RESULTS AND DISCUSSION}

\section{Overall sales of antibacterials}

The present pharmaco-epidemiological study shows that the use of antibacterials in aquaculture in Norway is very low. During the $6 \mathrm{yr}$ period 2011 to 2016, the total reported sales of antimicrobials for therapeutic use in farmed fish varied from $544 \mathrm{~kg}$ active substance in 2011 to a maximum in 2012 of $1590 \mathrm{~kg}$, declining gradually to $212 \mathrm{~kg}$ in 2016 (Fig. 1). During the same period, the production volume of farmed fish increased from 1.14 to 1.38 million $t$ (Table 1). Subsequently, the amount of antibacterials used varied from a maximum in 2012 of $1.21 \mathrm{mg} \mathrm{kg}^{-1}$ fish slaughtered down to $0.38 \mathrm{mg} \mathrm{kg}^{-1}$ in 2014 and $0.16 \mathrm{mg} \mathrm{kg}^{-1}$ in 2016 (Table 2). In a general perspective, the consumption of antibacterials in fish in 2015 was approximately one-tenth of the anti-

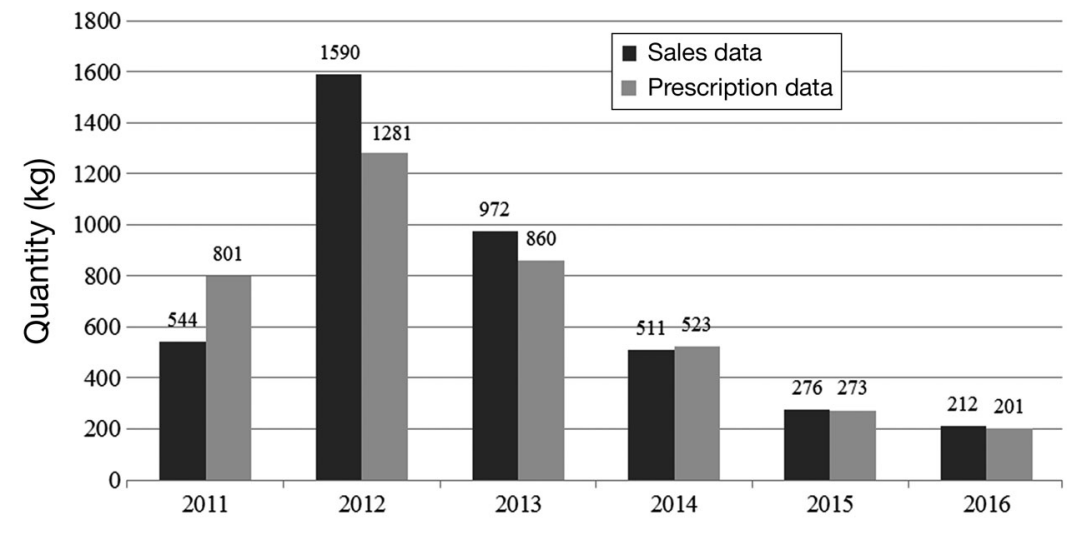

Fig. 1. Antibacterials sold for use in farmed fish in Norway, sold from wholesalers, pharmacies and feed mills, reported to the Norwegian Institute of Public Health, versus prescribed amounts calculated from prescription data obtained from the veterinary prescription register, VetReg from 2011 to 2016

Table 1. Annual production (t) of farmed fish by species for food consumption in Norwegian aquaculture from 2011-2016. Data from the Norwegian Directorate for Fisheries. Other species: mainly Arctic char, turbot and wolf fish

\begin{tabular}{|lcrrrrr|}
\hline Year & $\begin{array}{c}\text { Atlantic } \\
\text { salmon }\end{array}$ & $\begin{array}{c}\text { Rainbow } \\
\text { trout }\end{array}$ & $\begin{array}{c}\text { Atlantic } \\
\text { cod }\end{array}$ & Halibut & $\begin{array}{c}\text { Other } \\
\text { species }\end{array}$ & $\begin{array}{c}\text { Total } \\
\text { tonnes (t) }\end{array}$ \\
\hline 2011 & 1064868 & 58481 & 15273 & 2767 & 513 & 1141902 \\
2012 & 1232095 & 74593 & 10033 & 1741 & 582 & 1319044 \\
2013 & 1168324 & 71449 & 3770 & 1385 & 472 & 1245400 \\
2014 & 1258356 & 68910 & 1386 & 1257 & 497 & 1330406 \\
2015 & 1303346 & 72921 & 5 & 1243 & 465 & 1377980 \\
2016 & 1235263 & 87446 & 450 & 1461 & 562 & 1326229 \\
\hline
\end{tabular}


bacterial consumption for food-producing terrestrial animals in Norway the same year, which is also very low, being among the lowest in use of antibacterial VMPs of the 30 European countries for which data on consumption in animals, including fish, have been published (Anonymous 2017). For terrestrial foodproducing animals (including horses) in Norway in 2016, the sales of antibacterial VMPs normalised for by the biomass 'at risk' (population correction unit = PCU; 1 PCU = $1 \mathrm{~kg}$ ) was $10.1 \mathrm{mg} \mathrm{kg}^{-1}$ (Skov Simonsen \& Urdahl 2017). These data are not directly comparable with data on sales for fish shown in the present study because they are aggregated for many different animal species and production categories, but also because the antibacterial classes, and thus dosing used, differs from those used for farmed fish.

Analysis of DCDs (Table 2) showed that a volume corresponding to $\sim 0.85 \%$ of the fish produced in 2012 could have been subjected to antibacterial treatment, the proportion declining gradually to $0.14 \%$ in 2016 . Hence, there has been a continuous trend towards reduction in sales of antibacterial agents for use in farmed fish relative to produced biomass since 2011.

\section{Antibiotic classes sold}

Amphenicols (florfenicol) and quinolones (oxolinic acid) dominated in treatment of bacterial infections in fish during 2011 to 2016 (Table 2). In 2012 and 2013, oxolinic acid was prescribed the most, while florfenicol was the drug of choice the last $3 \mathrm{yr}$. According to the prescription data reported to VetReg, there were no indications of differences in the antibacterial classes or substances being prescribed to the different fish categories, production phases or disease diagnoses (data not shown).

\section{Fish species treated}

Based on the data from VetReg, it can be concluded that the major proportion of antibacterials prescribed, aggregated for all the study years, was for Atlantic salmon Salmo salar. The data show that $78 \%$ of total amounts prescribed were for this species, 16\% for 'others' (cleaner fish used for salmon lice control and other non-specified species), 5\% for marine species (Atlantic cod Gadus morhua, Atlantic halibut Hippoglossus hippoglossus, wolf fish Anarhichas lupus and turbot Scophthalmus maximus) and $0.5 \%$ for rainbow trout Oncorhynchus mykiss (Fig. 2). Of the total number of prescriptions for the study period, 35\% was for Atlantic salmon, $47 \%$ for other species, $16 \%$ for marine species and $1.5 \%$ for rainbow trout (Table 3 ). Of the total production of farmed fish for human consumption during these years, $94 \%$ was Atlantic salmon (Table 1), indicating overall much lower treatment incidence than for the other fish species.

\section{Treatments and diagnoses}

\section{Atlantic salmon S. salar}

Most of the prescriptions for Atlantic salmon were for fish in the fresh water production phase, comprising the fish categories fry and fingerlings (Table 3). In $2011,9 \%$ of the prescriptions were for fish in seawater, increasing to a maximum proportion of $34 \%$ in 2016. Still, due to higher weight of on-growers, and thus typically higher biomasses of fish for each treatment, the highest amounts of antibacterials were used in this production phase (Fig. 2), an overall of $83 \%$ of the total amounts being prescribed during the entire 6 yr period. Nine of the prescriptions for

Table 2. Sales of antibacterials for farmed fish in Norway for the period 2011 to 2016, and the sales of antibacterials in relation to overall biomass of fish slaughtered. Estimated biomass of fish which could have been treated with one cure with the volume antibacterials sold is calculated using national defined course doses (DCDs) in relation to overall biomass fish slaughtered each year

\begin{tabular}{|ccccccc|}
\hline Year & $\begin{array}{c}\text { Florfenicol } \\
(\mathrm{kg})\end{array}$ & $\begin{array}{c}\text { Oxolinic acid } \\
(\mathrm{kg})\end{array}$ & $\begin{array}{c}\text { Oxytetracycline } \\
(\mathrm{kg})\end{array}$ & $\begin{array}{c}\text { Total anti- } \\
\text { bacterials } \\
(\mathrm{kg})\end{array}$ & $\begin{array}{c}\text { Antibacterials sold/ } \\
\text { biomass slaughtered } \\
\left(\mathrm{mg} \mathrm{kg}^{-1}\right)\end{array}$ & $\begin{array}{c}\text { Biomass treated/ } \\
\text { biomass slaughtered } \\
\left.(\mathrm{DCD} \mathrm{kg})^{-1}\right)\end{array}$ \\
\hline 2011 & 331 & 212 & 1 & 544 & 0.48 & 0.0041 \\
2012 & 191 & 1399 & 1 & 1591 & 0.21 & 0.0085 \\
2013 & 300 & 672 & 0 & 972 & 0.38 & 0.0036 \\
2014 & 403 & 108 & 0 & 511 & 0.20 & 0.0018 \\
2015 & 194 & 82 & 0 & 276 & 0.16 & 0.0014 \\
2016 & 138 & 74 & 0 & 212 & \\
\hline
\end{tabular}



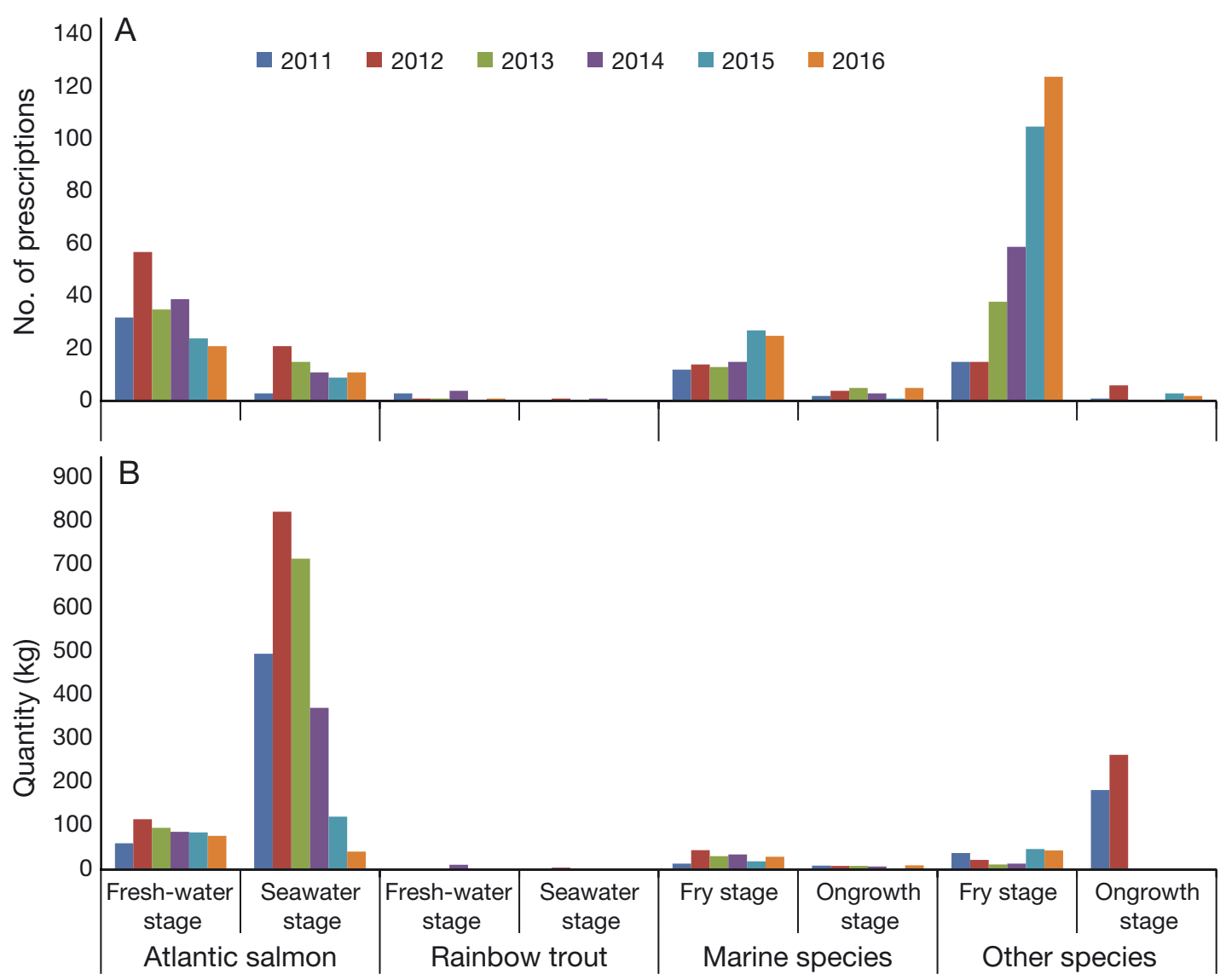

Fig. 2. (A) Number of prescriptions and (B) mass of antibacterial agents prescribed for different fish species at different life stages. Marine species include Atlantic cod, halibut, turbot and wolf fish. Other species include cleaner fish and fish species reported as 'others'

Atlantic salmon in seawater were for brood fish, the remaining being for on-growers. In 2016, only 11 prescriptions for antibacterials were for salmon in seawater, 5 for brood fish and 6 for on-growers. This indicates that in 2016, on-growers in $<1 \%$ of the 799 farming sites reported to be active for this category of fish (Directorate of Fisheries, www.fiskeridir.no) were subjected to an antibacterial treatment.

The diagnoses given as the reason for the treatments of the different fish species during the $5 \mathrm{yr}$ period 2011 to 2016 are shown in Table 3. For Atlantic salmon, the non-specific diagnosis 'bacterial infection' was given for $71 \%$ of the prescriptions. This 'diagnosis' is thought to be selected in cases where the results of clinical and pathological examinations correspond to a bacterial infection, when bacteriological examination does conclude with a non-specific infection, or if the prescription is issued before a bacteriological diagnosis is completed.

The numbers of treatments against cold-water vibriosis in Atlantic salmon on-growers were 9 and 3 in 2012 and 2013, respectively (Table 3), while for the other years, there were no treatments reported for this disease. A limited epidemic of cold-water vibriosis was registered in northern Norway during these years, probably partly caused by changes made in composition and dose for some vaccines and partly due to nonoptimal vaccination procedures (Lillehaug et al. 2013). This epidemic might explain the marked peak in overall use of antibacterials (Fig. 1) and particularly for seareared Atlantic salmon (Fig. 2B) the same years.

Except for the outbreaks of cold-water vibriosis, the specific infections vaccinated against are under control in Atlantic salmon in seawater. The fish are vaccinated as fingerlings or smolt rather late in the freshwater phase to protect the fish after sea transfer, which may explain a few outbreaks of the diseases vaccinated against in freshwater. Cold-water vibriosis, classic vibriosis, yersiniosis, winter ulcers and infection with Aeromonas (Table 3) are all conditions which can be vaccinated against. However, it is likely that the outbreaks occurred prior to vaccination in freshwater or before immunity was fully developed. 
Table 3. Number of prescriptions of antibacterial agents according to year and disease diagnoses reported for different fish species and production phase in Norwegian fish farms during the period 2011 to 2016, also giving weight ranges for medicated fish

\begin{tabular}{|c|c|c|c|c|c|c|c|}
\hline & 2011 & 2012 & 2013 & 2014 & 2015 & 2016 & $\begin{array}{l}\text { Weight (g) of fish } \\
\text { treated (min.-max.) }\end{array}$ \\
\hline \multicolumn{8}{|c|}{ Atlantic salmon, on-growers and brood fish } \\
\hline Bacterial infection & 3 & 8 & 10 & 10 & 8 & 9 & $50-6600$ \\
\hline Cold-water vibriosis & & 9 & 3 & & & & $1000-2500$ \\
\hline Vibriosis & & 4 & & & & & $55-800$ \\
\hline Yersiniosis & & & & & & 1 & 300 \\
\hline Winter ulcers & & & 2 & 1 & & 1 & $100-687$ \\
\hline \multicolumn{8}{|c|}{ Atlantic salmon, fry and fingerlings } \\
\hline Bacterial infection & 27 & 40 & 22 & 29 & 16 & 15 & $1-300$ \\
\hline Cold-water vibriosis & & & 1 & 2 & & & $10-50$ \\
\hline Vibriosis & 2 & 7 & 5 & 2 & 4 & 1 & $2-400$ \\
\hline Aeromonas infection & & 4 & 1 & 3 & & 1 & $28-170$ \\
\hline Yersiniosis & 3 & 4 & 6 & 3 & 4 & 4 & $3-400$ \\
\hline Winter ulcers & & 2 & & & & & $10-80$ \\
\hline \multicolumn{8}{|l|}{ Rainbow trout } \\
\hline Bacterial infection & 3 & 2 & 1 & 3 & & & $4-700$ \\
\hline Vibrio infections & & & & 2 & & 1 & $28-55$ \\
\hline \multicolumn{8}{|c|}{ Marine species (Atlantic cod, halibut, turbot, wolf fish) } \\
\hline Bacterial infection & 13 & 3 & 17 & 15 & 24 & 13 & $1-1590$ \\
\hline Aeromonas infection & & 2 & 1 & 2 & & 8 & $2-500$ \\
\hline Vibrio infections & 1 & 13 & & 1 & 5 & 9 & $4-1200$ \\
\hline \multicolumn{8}{|c|}{ Other species (including cleaner fish) } \\
\hline Bacterial infection & 13 & 16 & 32 & 30 & 70 & 94 & $1-2200$ \\
\hline Aeromonas infection & & & & 1 & & & 40 \\
\hline Vibrio infections & 2 & 4 & 5 & 28 & 38 & 32 & $1-2050$ \\
\hline Yersiniosis & 1 & 1 & 1 & & & & $1-60$ \\
\hline Total number of prescriptions & 68 & 119 & 107 & 132 & 169 & 189 & \\
\hline
\end{tabular}

\section{Rainbow trout O. mykiss}

Rainbow trout is the second largest fish-farming industry in Norway. This species is usually vaccinated with the same vaccine products as Atlantic salmon. Almost all treatments in rainbow trout in the period 2011 to 2016 were against non-specific 'bacterial infection'; only 2 cases were against vibriosis (Table 3). These 2 cases were reported for 'fingerlings' in freshwater within the weight span of 50 to 55 $g$, which corresponds to fish at the point of vaccination and sea transfer, when freshwater is often supplemented with seawater to help the fish adapt to the new environment prior to sea transfer. This procedure may expose the fish to $V$. anguillarum before a vaccine response is fully developed.

\section{Marine species}

From 2011 to 2016, the proportion of marine species in aquaculture declined from 2.3 to $0.2 \%$ (Table 1). In the same period, the annual number of prescriptions for marine fish species Atlantic cod G. morhua, Atlantic halibut $H$. hippoglossus, turbot $S$. maximus and wolf fish A. lupus was relatively stable (Table 3). Also in these species, 'bacterial infection' was the most common 'indication' given for treatment. Vaccines against infections caused by $V$. anguillarum and $A$. salmonicida have, to some extent, been used in these species (Mikkelsen et al. 2007, Lund et al. 2008); however, they are not subject to systematic vaccination programmes, and the effectiveness of vaccination in these species under field conditions is unclear. This may explain the higher number of prescriptions caused by these infections relative to the production of these marine fish species (Table 3). Even for the marine species, most of the prescriptions were for production stages before on-growth, given as 'fry' or 'fingerlings' (data not shown).

\section{Other species}

In addition to prescriptions originally stating 'other' for 'fish species' in the web application for VetReg, 
the category 'other species' in Table 3 consists of different species, wild-caught or cultivated, used as 'cleaner fish' to control salmon louse. These species include lumpfish Cyclopterus lumpus, goldsinny wrasse Ctenolabrus rupestris, corkwing wrasse Symphodus melops and ballan wrasse Labrus bergylta. The use of cleaner fish has increased significantly over many years: in 2016, a total of 36 million fishes were transferred to net pens holding salmonid ongrowers (Directorate of Fisheries, www.fiskeridir.no).

Of all prescriptions from 2011 to 2016, 47\% were for the category 'other species', and in 2016, as much as $67 \%$ of the total number of prescriptions were for this category of fishes. 'Bacterial infection' was reported as the diagnosis in two-thirds of the prescriptions, and of the remaining, Vibrio infection was the specific diagnosis given in $96 \%$ of the prescriptions. Different Vibrio species have been isolated from cleaner fish in Norway, including $V$. anguillarum serovars $\mathrm{O} 1$ and $\mathrm{O} 2 \alpha$, as well as non-typable isolates, V. ordalii, V. splendidus, V. logei, V. tapetis and V. wodanis (Hjeltnes et al. 2017).

\section{Overall situation: bacterial diseases in farmed fish}

Prescriptions of antibacterials were to a great extent reported to VetReg as non-specific bacterial infections for all fish species and production stages, and not by specific infectious agents. The major specific bacterial infections - vibriosis, cold-water vibriosis and furunculosis - seem to be under full control by use of vaccination programmes. A similar study based on prescription data for the period 1991 to 2000 concluded that the reduction in sales from 27.5 tons of active substance in 1992 to $6.1 \mathrm{t}$ in 1993, and further to 1.4 tons in 1994, was due to the implementation of full-scale vaccination programmes with efficient vaccines against vibriosis, cold-water vibriosis and furunculosis in salmonids from 1993 (Lillehaug et al. 2003). Since then, the vaccination programme has been followed, and vaccines have also been introduced against the bacterial infections winter ulcers caused by Moritella viscosa (Colquhoun \& Lillehaug 2014) and yersiniosis caused by Yersinia ruckeri (Bridle \& Nowak 2014). During these $25 \mathrm{yr}$, the major disease problems in farmed fish in Norway have been caused by viruses (i.e. infectious salmon anaemia and pancreas disease) and parasites (i.e. salmon lice and amoebic gill disease) (Norwegian Veterinary Institute, www.vetinst.no).

The VetReg system offers only a limited number of specific bacterial agents or diseases, and the category 'Bacterial infection - unspecified bacterial agent', as default diagnoses. This may have led to other specific bacterial agents being classified as 'unspecified'. For instance, the Fish Health Report 2016 (Norwegian Veterinary Institute) reports that Tenacibaculum spp. may be isolated from ulcers, including winter ulcers, in salmonids in seawater, as well as from fin rot and other dermal infections in cleaner fish. Moreover, Tenacibaculum maritimum was diagnosed for the first time in turbot (S. maximus), causing jaw ulcers (Norwegian Veterinary Institute). This indicates that a longer list of default specific agents, or establishing a possibility to report agents which are not specified, would give more valuable disease information.

This extremely favourable situation with very low use of antibacterials is considered to be primarily a consequence of the extensive use of vaccines in Norwegian salmonid aquaculture. Other general biosecurity measures, which have been implemented and regulated by law, may also have contributed, such as compulsory health controls in fish farms, regulation of transport of live fish, only a single generation of fish at 1 site ('all in-all out'), fallowing between generations, disinfection of water supply in hatcheries and disinfection of wastewater from slaughterhouses.

\section{Material and indicators}

The present study is based on 2 different sets of data: one is the total mass of antibacterials sold from wholesalers, pharmacies and feed mills producing medicated feed for use in Norwegian aquaculture, and the other is prescription data for antibacterials reported, mainly by feed mills, to VetReg. Fig. 1 shows the consumption of antibacterials per year for the 2 different data sets. The data reported for 2011 and 2012 differ significantly between the 2 data sets: the first year the volumes reported to VetReg were significantly higher than the sales data, the next year showed a reverse ratio. The difference was moderate in 2013, still giving somewhat lower volumes from VetReg, while in the last $3 \mathrm{yr}, 2014$ to 2016, the values were close to identical for the 2 databases. This high degree of agreement between data from 2 different sources the last 3 yreas substantiates the quality and reliability of both reporting and registration systems.

The explanation for the deviations in the first years is likely that the system for reporting prescription data to VetReg required improvement based on experiences gained during implementation. In later 
years, reporting has been optimised, and the system has been further developed to reduce risks of manual punching errors, as confirmed by the present results.

The sales of antibacterials reported from the wholesalers can be considered the most accurate for the entire study period. Therefore, these data were used to present overall consumption of antibacterials per year, as well as calculate the amount of antibacterials used related to total fish production, given as mg of active substance of antibacterial agent per $\mathrm{kg}$ of slaughtered fish, and DCDs, as calculated according to the method of Grave et al. (1996). Prescription data of antibacterials for fish shows that most treatments are for early life stages of fish (fry, fingerlings) as well as fish that are not produced for human consumption, i.e. cleaner fish. If only antibacterials prescribed for Atlantic salmon S. salar in the seawater production phase in 2016 are included in the calculations, the usage goes down from 0.20 to $0.03 \mathrm{mg}$ antibacterials $\mathrm{kg}^{-1}$ slaughtered salmon.

The prescription data are considered to be adequate to give a relatively detailed description of the objectives of the antibacterial treatments regarding choice of antibacterial agent and characterisation of the fish populations being treated, fish species and production stage.

\section{Human health aspects}

Treatment with antibacterials, in humans and in animals, is the major risk factor for the development and dissemination of resistant bacteria and gene coding for antibacterial resistance. This may also apply to aquaculture (Caruso 2016). In the case of foodproducing animals, antibiotic-resistant bacteria and resistance genes can be transferred to humans through food products. Therefore, the use of antibacterials should be as low as possible without compromising animal welfare, which emphasizes the importance of prophylactic methods to control disease. The occurrence of resistance is associated with the quantities of antibacterials used. Due to the low treatment incidence with antibacterials in farmed fish, the risk of humans being exposed to antibacterial-resistant bacteria from farmed fish cultivated in Norway is very low.

In terms of antibacterial resistance and food safety, the choice of classes of antibacterials, in addition to quantities of antibacterials used for food producing animals, is important. The World Health Organization has classified certain antimicrobial classes as 'Highest Priority Critically Important Antimicrobials' for human medicine in the so-called CIA list (Collignon et al. 2016). The CIA list is intended for public health and animal health authorities, practicing physicians and veterinarians, as well as other interested stakeholders involved in managing antimicrobial resistance, to ensure that highest priority CIA are used prudently both in human and veterinary medicine.

One of the antimicrobial classes listed on the highest priority CIA list are the quinolones. During the first years of this study period, antibacterial sales were dominated by a quinolone (oxolinic acid), but in the last 3 years, more amphenicols (florfenicol) were sold. These classes have replaced tetracyclines and combination products of sulphonamides and trimethoprim, which were the classes used in Norwegian aquaculture during the early 1990s.

\section{CONCLUSIONS}

This pharmaco-epidemiological study confirms that in farmed salmonid fish in Norway, the major specific bacterial infections which can be vaccinated against are almost completely under control. The Norwegian fish farming industry uses very small volumes of antibacterial agents, and when taking increased production into account, the use of antibacterials relative to the produced biomass of fish has been decreasing since the early 1990s. The majority of prescriptions for farmed fish are issued to treat the fish category 'other species', including cleaner fish, for non-specific bacterial infections. Most prescriptions for salmonid fish are at early production stages, long before the fish reach market size. The insignificant consumption of antibacterial agents in Norwegian aquaculture indicates that the risk of development of antimicrobial-resistant bacteria in farmed fish, and thus the likelihood of transmission of resistance to humans, is very low.

\section{LITERATURE CITED}

Anonymous (2017) Sales of veterinary antimicrobial agents in 30 European countries in 2015. European Medicines Agency, EMA/ 184855/2017, European Surveillance of Veterinary Antimicrobial Consumption (ESVAC)

Bridle A, Nowak B (2014) Vaccination against yersiniosis. In: Gudding R, Lillehaug A, Evensen Ø (eds) Fish vaccination. Wiley Blackwell, Chichester, p 226-235

Caruso G (2016) Antibiotic resistance in fish farming environments: a global concern. J Fish Sci. Com 10(4):9-13

Collignon PC, Conly JM, Andremont A, McEwen SA, Awa Aidara-Kane A (2016) World Health Organization ranking of antimicrobials according to their importance in 
human medicine: a critical step for developing risk management strategies to control antimicrobial resistance from food animal production. Clin Infect Dis 63:1087-1093

Colquhoun D, Lillehaug A (2014) Vaccination against vibriosis. In: Gudding R, Lillehaug A, Evensen $\varnothing$ (eds) Fish vaccination. Wiley Blackwell, Chichester, p 172-184

Egidius E (1987) Import of furunculosis to Norway with Atlantic salmon smolts from Scotland. ICES Mariculture Committee Report CM 1987/F:8

Grave K, Engelstad M, Søli NE, Håstein T (1990) Utilization of antibacterial drugs in salmonid farming in Norway during 1980-1988. Aquaculture 86:347-358

Grave K, Markestad M, Bangen M (1996) Comparison in prescribing patterns of antibacterial drugs in salmonid farming in Norway during the periods 1989-1994 and 1980-1988. J Vet Pharmacol Ther 19:184-191

* Grave K, Lillehaug A, Lunestad BT, Horsberg TE (1999) Prudent use of antibacterial drugs in Norwegian aquaculture? Surveillance by the use of prescription data. Acta Vet Scand 40:185-195

Håstein T (1975) Vibriosis in fish. A clinical, pathological and bacteriological study of the disease in Norwegian fish farms. PhD dissertation, University of Stirling

Hjeltnes B, Bornø G, Jansen MD, Haukaas A, Walde C (eds) (2017) Fish health report 2016. www.vetinst.no/rapporterog-publikasjoner/rapporter/2017/fish-health-report-2016

Lillehaug A (1989) A survey on different procedures used for vaccinating salmonids against vibriosis in Norwegian fish farming. Aquaculture 83:217-226

Lillehaug A (1990) A field trial of vaccination against coldwater vibriosis in Atlantic salmon (Salmo salar L.). J Fish Dis 84:1-12

Editorial responsibility: Lori Gustafson, Fort Collins, Colorado, USA
Killehaug A, Lunder T, Poppe TT (1992) Field testing of adjuvanted furunculosis vaccines in Atlantic salmon Salmo salar L. J Fish Dis 15:485-496

* Lillehaug A, Lunestad BT, Grave K (2003) Epidemiological description of bacterial diseases in Norwegian aquaculture - a description based on antibiotic prescription data for the ten-year period 1991 to 2000. Dis Aquat Org 53: $115-125$

Lillehaug A, Colquhoun D, Alarcon M, Skjelstad HR, Fyrand K, Hovland T, Vollstad D (2013) Kaldtvannsvibriose - et gammelt problem kommer tilbake? Nor Fiskeoppdrett 38:46-49

K Lund V, Mikkelsen H, Schrøder MB (2008) Comparison of atypical furunculosis vaccines in spotted wolffish (Anarhicas minor O.) and Atlantic halibut (Hippoglossus hippoglossus L.). Vaccine 26:2833-2840

Markestad A, Grave K (1997) Reduction of antibacterial drug use in Norwegian fish farming due to vaccination. Dev Biol Stand 90:365-369

Midtlyng PJ (1997) Vaccination against furunculosis. In: Bernoth EM, Ellis AE, Midtlyng PJ, Olivier G, Smith PR (eds) Furunculosis - multidisciplinary fish disease research. Academic Press, London, p 382-404

Mikkelsen H, Lund V, Martinsen LC, Gravningen K, Schrøder MB (2007) Variability among Vibrio anguillarum O2 isolates from Atlantic cod (Gadus morhua L.): characterisation and vaccination studies. Aquaculture 266:16-25

Skov Simonsen G, Urdahl AM (2017) NORM/NORM-VET 2016. Usage of antimicrobial agents and occurrence of antimicrobial resistance in Norway. Norwegian Veterinary Institute, Tromsø/Oslo

Submitted: December 15, 2017; Accepted: February 20, 2018 Proofs received from author(s): April 9, 2018 